\title{
The impact of D-cycloserine and sarcosine on in vivo frontal neural activity in a schizophrenia-like model
}

\author{
Lulu Yao ${ }^{1}$, Zongliang Wang ${ }^{1}$, Di Deng ${ }^{1}$, Rongzhen Yan', Jun Ju and Qiang Zhou ${ }^{1,2^{*}}$
}

\begin{abstract}
Background: N-methyl-D-aspartate receptor (NMDAR) hypofunction has been proposed to underlie the pathogenesis of schizophrenia. Specifically, reduced function of NMDARs leads to altered balance between excitation and inhibition which further drives neural network malfunctions. Clinical studies suggested that NMDAR modulators (glycine, D-serine, D-cycloserine and glycine transporter inhibitors) may be beneficial in treating schizophrenia patients. Preclinical evidence also suggested that these NMDAR modulators may enhance synaptic NMDAR function and synaptic plasticity in brain slices. However, an important issue that has not been addressed is whether these NMDAR modulators modulate neural activity/spiking in vivo.
\end{abstract}

Methods: By using in vivo calcium imaging and single unit recording, we tested the effect of D-cycloserine, sarcosine (glycine transporter 1 inhibitor) and glycine, on schizophrenia-like model mice.

Results: In vivo neural activity is significantly higher in the schizophrenia-like model mice, compared to control mice. D-cycloserine and sarcosine showed no significant effect on neural activity in the schizophrenia-like model mice. Glycine induced a large reduction in movement in home cage and reduced in vivo brain activity in control mice which prevented further analysis of its effect in schizophrenia-like model mice.

Conclusions: We conclude that there is no significant impact of the tested NMDAR modulators on neural spiking in the schizophrenia-like model mice.

Keywords: NMDARs, Schizophrenia, NMDAR co-agonist, Calcium imaging, Single unit recording

\section{Background}

The glutamate hypofunction model of schizophrenia proposes that reduced function of glutamate receptors, especially NMDA subtypes on the inhibitory neurons leads to an imbalanced excitation and inhibition, and results in altered neural network functions (such as oscillations and working memory) [1-4]. These altered functions are proposed to drive the pathogenesis of schizophrenia and are likely contribute to on-going schizophrenia pathology. Thus, enhancing NMDARs may have therapeutic potentials in treating schizophrenia [5-8].

\footnotetext{
*Correspondence: zhouqiang.sz@pku.edu.cn

${ }^{1}$ School of Chemical Biology and Biotechnology, Peking University Shenzhen Graduate School, Shenzhen 518055, China

${ }^{2}$ State Key Laboratory of Chemical Oncogenomics, Key Laboratory of

Chemical Genomics, Peking University Shenzhen Graduate School, Shenzhen 518055, China
}

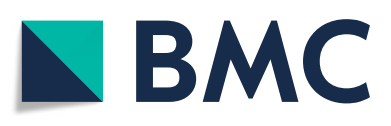

(c) The Author(s). 2019 Open Access This article is distributed under the terms of the Creative Commons Attribution 4.0 International License (http://creativecommons.org/licenses/by/4.0/), which permits unrestricted use, distribution, and reproduction in any medium, provided you give appropriate credit to the original author(s) and the source, provide a link to the Creative Commons license, and indicate if changes were made. The Creative Commons Public Domain Dedication waiver (http://creativecommons.org/publicdomain/zero/1.0/) applies to the data made available in this article, unless otherwise stated. quires binding of glutamate, co-agonist (glycine or Dserine) and postsynaptic depolarization [8-11]. To avoid the excitotoxicity of direct activation of the NMDAR, targeting co-agonist/glycine binding site for enhancing NMDAR activation may be a good strategy for schizophrenia treatment [12-14]. The concentrations of coagonist were reduced in the brains of schizophrenia patients [15-18], and administering NMDAR co-agonists (glycine, D-serine or D-cycloserine (DCS), etc) improved functions in schizophrenia patients in clinical trials [19, 20]. However, positive outcomes were not seen in some clinical trials [21-23], especially larger trials [24-26]. In addition to directly administering NMDAR co-agonists, another widely pursued approach is to elevate the endogenous glycine level by blocking its uptake using selective glycine transporter inhibitors, such as glycine 
transporter 1 (GlyT-1) inhibitors [27-29]. This approach takes advantage of the unique distribution of GlyT-1 in the brain. GlyT-1 plays a crucial role in regulating the availability of glycine near the vicinity of NMDARs and is expressed at both presynaptic and postsynaptic regions of glutamatergic synapses, as well as on the astrocytes [30-32]. GlyT-1 inhibitors have been recently tested in clinical trials aiming to treat negative symptoms in schizophrenia [28, 29, 33, 34]. Bitopertin, a GlyT-1 inhibitor developed by Hoffmann-La Roche, has reached phase III clinical trial for treating negative or positive symptoms in schizophrenia, but was halted due to lack of efficacy in improving negative symptoms which is the primary endpoint for these trials $[35,36]$. Thus, the lack of success or at least inconsistent efficacy in treating schizophrenia by the NMDAR modulators has raised the question of whether enhancing NMDARs is the appropriate strategy in treating schizophrenia. Therefore, a careful analysis of the potential mechanisms and efficacy of these enhancers is critical for understanding why this approach has not met with success.

Clinical trials have focused on and aimed at improving functions or reducing symptoms in the schizophrenia patients. Although these are important readouts in determining the therapeutic values of a drug, it does not necessarily provide essential information on target engagement (i.e., whether enhanced activation of NMDARs has been achieved with drug on board) and whether this engagement translates to improved neural functions directly related to NMDAR activation, such as neural spiking. Elevating the level of co-agonist by exogenous glycine/D-serine or GlyT-1 inhibitor increased the activation of NMDARs in brain slices, and NMDA-induced neuronal spiking in vivo [37-41]. The expression of LTP is enhanced in the presence of glycine in vitro [42, 43], but whether glycine/D-serine/DCS is sufficient to increase neural spiking has not been systematically examined.

Neuregulin1 (NRG1) is a transmembrane protein with an epidermal growth like-domain, and important for neuronal developmental process and functions [44]. NRG1and its receptor ErbB4 are susceptibility genes in schizophrenia $[45,46]$. In the postmortem brains of schizophrenia, expression of NRG1 mRNA and protein was upregulated [47, 48]. NRG1 signaling could be mediated via canonical and non-canonical pathways, with the former requires NRG1 binding to ErbB4 receptor, and the latter not [44]. We used an anti-Neuregulin1 (anti-Nrg1) antibody to induce schizophrenia-like phenotypes, including hyperlocomotion and impaired prepulse inhibition [49, 50]. Injection of this antibody stabilized the full length Nrg1 and caused it to accumulate, based on in vitro evidence of robust increase of full length NRG1 in Nrg1-expressing 293 cells treated with
anti-NRG1 antibodies. It was suggested that anti-Nrg1 antibodies likely activate ErbB4-independent signaling and resulted in increased phosphorylation of cofilin [50]. This signaling pathway is similar to that reported with overexpression of NRG1 [51]. The advantage of this anti-Nrg1 antibody model over the more widely used genetic, pharmacological or lesion models is that schizophrenia-like phenotypes can be induced in the adult mice (Ju et al., 2019) and thus offers one rare opportunity to study late/adult-onset schizophrenia model. At least $20 \%$ of schizophrenia cases are of late/adult onset after the age of 40 years [52]. We tested the effect of NMDAR modulators on this schizophrenia-like model.

In the current study, we examined whether glycine, DCS or sarcosine significantly affects neuronal spiking in schizophrenia-like model mice. We have used both in vivo $\mathrm{Ca}^{2+}$ imaging and in vivo single unit recording. Somatic $\mathrm{Ca}^{2+}$ responses allowed us to measure neuronal spiking activity in certain types of neurons (depend on the promoter used), while in vivo single unit recording allows measurement of changes in both single spikes and burst spikes in response to administration of NMDAR modulators. We have observed an increased neural activity in the schizophrenia-like model mice induced by anti-Nrg1 antibodies, but did not find any significant change in neural activity using both measurements after administration of NMDAR modulators in either control or schizophrenia-like model mice.

\section{Methods}

\section{Animals}

C57BL/6 wildtype mice were purchased from Guangdong Medical Laboratory Animal Center. All animal experiments were performed in accordance with the ARRIVE guidelines on the Care and Use of Experimental Animals, approved by the Peking University Shenzhen Graduate School Animal Care and Use Committee. To establish a schizophrenia-like model, anti-Nrg1 antibody (a gift from Genentech) was intraperitoneally injected into 8 weeks old male mice $(20 \mathrm{mg} / \mathrm{kg}$, ) three times within a 2 week period, while control mice were intraperitoneally administered with anti-Ragweed (anti-Rag) $(20 \mathrm{mg} / \mathrm{kg})[49,50]$. Mice were randomly divided into the two groups. All efforts were made to reduce the number of animals used and to minimize animal suffering during the experiment. We anesthetized the mice with isoflurane inhalation or intraperitoneal injection of phenobarbital sodium $(100 \mathrm{mg} / \mathrm{kg})$.

\section{Two-photon imaging}

\section{Surgery for two-photon imaging}

Mice of 7 8-weeks of age were anaesthetized by intraperitoneal injection $(100 \mathrm{mg} / \mathrm{kg})$ of phenobarbital sodium. The fur over the injection site was shaved and an 
incision was made, and a small hole was drilled. A glass pipette was advanced towards the imaging area to at a $20^{\circ}$ angel to minimize tissue disturbance. Each mouse was injected with virus (under either CAG, CaMKII or Synapsin) coding GCaMP6s (Penn Vector Core) in the frontal association cortex (coordinates: Bregma $+2.5-2.8 \mathrm{~mm}$, midline: $\pm 1.0 \mathrm{~mm}$, ventral: $0.2 \sim 0.3 \mathrm{~mm}$ ) [53]. The skin was then sutured to allow viral expression for 14 days in the home cage prior to two-photon imaging. During this viral expression period, anti-Nrg1 antibody or anti antiRag antibody was injected into mice i.p.

Calcium responses in the somata of layer II/III FrA neurons were collected since FrA has significant relevance to schizophrenia pathology and is more accessible for in vivo two photon imaging than medial prefrontal cortex [53, 54] (Fig. 1a). CAG is a pan-neuronal promoter that does not distinguish between excitatory and inhibitory neurons, while CaMKII allows selective expression of GCaMP6s in the excitatory neurons. By using these two promoters, we can evaluate the impact of NMDAR modulators on either the entire neuronal population or excitatory neurons selectively.

Under intraperitoneal injection of phenobarbital sodium $(100 \mathrm{mg} / \mathrm{kg})$, the fur over most of the scalp, skin and connective tissues over the skull were removed. The mouse head was held by placing two steel bars centered on the region to be imaged. A thick layer of freshly mixed dental cement was applied to keep the bars in place. Mice were put back to their home cages and imaging was performed on the next day.

\section{Imaging and analysis}

High-speed micro-drill was used to thin $(20 \mu \mathrm{m})$ circular area of skull [55]. A 25× objective (N.A. 1.05; 2X digital zoom) was used to image in time-lapse mode with the image size of $512 \times 512$ pixels and the temporal resolution is $1.109 \mathrm{~s}$ per frame (about $0.9 \mathrm{~Hz}$ ). Imaging was performed for 2 3 times to establish a basal level of calcium responses prior to administration of MK-801 $(0.3 \mathrm{mg} / \mathrm{kg})$ in wild type mice, DCS $(30 \mathrm{mg} / \mathrm{kg}$, i.p) or sarcosine $(0.3 \mathrm{~g} / \mathrm{kg}$ or $1 \mathrm{~g} / \mathrm{kg}$, i.p) in schizophrenia-model mice. About $30 \mathrm{~min}$ after dosing, images were taken for $1 \mathrm{~h}$ with an interval of $10 \mathrm{~min}$. The selection of this imaging time frame was based on the published results on the time taken for DCS and glycine to rise significantly after dosing. For DCS, it was reported that the brain concentration of DCS increased to $0.68 \pm 0.28$ to $0.86 \pm$ $0.37 \mu \mathrm{mol} / \mathrm{g}$ at 15 to $60 \mathrm{~min}$ following $320 \mathrm{mg} / \mathrm{kg}$ i.p [56]. For sarcosine, the concentration in the serum was about 18 to $25 \mu \mathrm{mol} / \mathrm{L}$ at 30 to $120 \mathrm{~min}$ following $2 \mathrm{~g} / \mathrm{d}$ oral intake [57], and the availability of glycine increased by 50 to $100 \%$ at 20 to $60 \mathrm{~min}$ following i.p [58]. On the next day, a different drug was injected if the mouse was in good condition (no serious inflammation, no bleeding in the thinned-skull area); otherwise, the mouse was sacrificed. After completion of experiments, mice were euthanized with minimum pain using carbon dioxide.

Regions-of-interest (ROIs) were manually selected in Image J software (NIH) to include all neuronal somata that appeared in all time-lapse image sets. We reported time series as $\Delta \mathrm{F} / \mathrm{F}=\left(\mathrm{F}-\mathrm{F}_{0}\right) / \mathrm{F}_{0}$, where $\mathrm{F}$ is the fluorescence signal after background subtraction, and $F_{0}$ is the mean of minimum fluorescence signal during a baseline period. The threshold for determining calcium signal was calculated as three times the standard deviation (SD). To calculate the integrated area/total activity, the area under $\mathrm{Ca}^{2+}$ responses within $1 \mathrm{~min}$ was integrated using Origin 7.0 software. For experiments using CAG promoter and CaMKII promoter (data shown in Figs. 3 and 4), neurons with their nucleus filled with fluorescence were not included in the analysis. For the MK-801 and sarcosine experiments (data shown in in Figs. 1 and

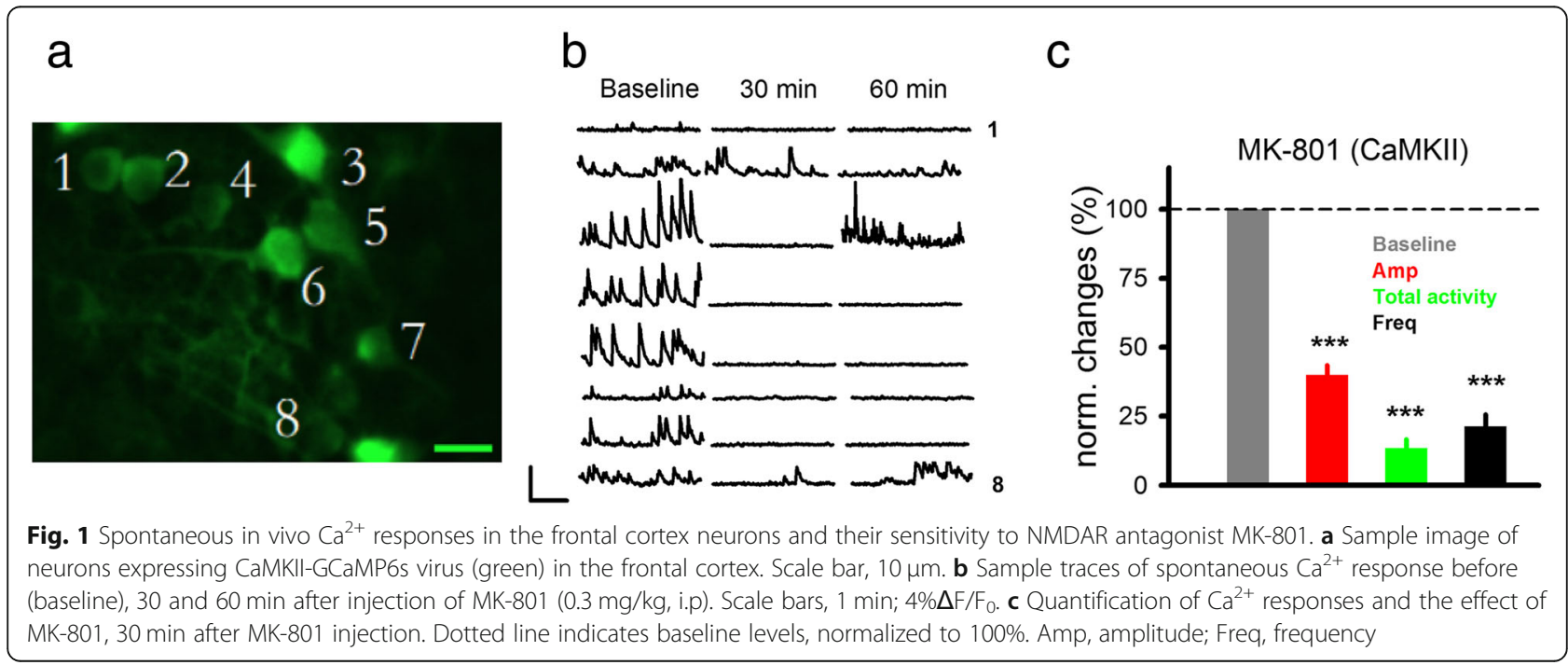


5), about $70 \%$ of neurons had nucleus filled with fluorescence. However, we found that all imaged neurons (whether they were filled or not) respond in the same way to MK-801 or sarcosine injection. Thus, all neurons were included in the analysis for these two experiments.

\section{In vivo single unit recording Surgery and recordings}

Wild type mice, mice injected with anti-Nrg1 antibody or anti-Rag (control) antibody were anesthetized with isoflurane and secured in a stereotaxic frame. As previously described [59], a multi-wire electrode set was unilaterally implanted aiming at medial prefrontal cortex (mPFC) with the following coordinates: $1.94 \mathrm{~mm}$ anterior to Bregma; $0.4 \mathrm{~mm}$ lateral to midline; $2.65 \mathrm{~mm}$ ventral from the cortical surface. After surgery, mice were allowed to recovery for 7 to 14 days. Neuronal activity was digitized at $30 \mathrm{kHz}$ and band-pass filtered from 250 $\mathrm{Hz}$ to $5 \mathrm{kHz}$. During recording, $10 \mathrm{~min}$ baseline spike rate was collected before drug injection (Saline or DCS $(30 \mathrm{mg} / \mathrm{kg})$ or MK-801 (0.3 mg/kg), all i.p) and recorded for another 60 to $90 \mathrm{~min}$ after drug injection. Mice were euthanized with carbon dioxide after completion of experiments.

\section{Spike sorting and analysis}

Analysis was based on methods published previously [59]. Briefly, waveforms of all recorded neurons were aligned using an offline-sorter software (Plexon). The principal component analysis (PCA) was then used to calculate the principal component score of the unsorted neuronal waveforms, and scores were plotted in a threedimensional principal component spaces. Burst spikes are based on the following criteria: (1) inter spike interval less than $15 \mathrm{~ms}$; (2) spike count in one burst larger than 2; (3) inter-burst interval longer than 100 ms. Relative change in spike rate (SR) is calculated as: Mean firing rate (after drug injection) /Mean firing rate (before drug injection) $\times 100(\%)$.

\section{Open field test}

Measurement of locomotion was based on method described previously [49]. In brief, mice were placed in the testing room for $1-2 \mathrm{~h}$ to be familiar with the environment prior to testing. Total distance traveled and time spent in the center area during a $60 \mathrm{~min}$ period was recorded using ANY-maze software (Global Biotech Inc.). D-cycloserine $(30 \mathrm{mg} / \mathrm{kg})$ or glycine $(1.6 \mathrm{~g} / \mathrm{kg})$ was injected (i.p) after $30 \mathrm{~min}$ in the open field.

\section{Statistics}

In general, normalized values were calculated as percentage change from baseline. Data can be fitted with a Gaussian distribution and were analyzed using two-way
ANOVA with Bonferroni post-tests, unpaired t-test or paired t-test, and presented as mean \pm SEM using Graph prism. Significant levels were set at $P<0.05 *, P<0.01$ **, $P<0.001$, ***.

\section{Results}

In vivo $\mathrm{Ca}^{2+}$ imaging and in vivo single unit recording were used to examine potential modulation of neuronal activity by NMDAR modulators in both schizophrenialike model and control mice. These two approaches are complementary to each other and provide a comprehensive view with both spatial and temporal resolution of in vivo neural activity, as well as contribution of excitatory neurons.

\section{In vivo $\mathrm{Ca}^{2+}$ signals and the effects of NMDAR inhibitor MK-801}

To obtain in vivo $\mathrm{Ca}^{2+}$ signals, virus (under either CAG or CaMKII promoter) coding GCaMP6s was injected into mouse frontal association cortex (FrA). We focused on the $\mathrm{Ca}^{2+}$ responses in the somata of layer II/III FrA neurons since FrA has significant relevance to schizophrenia pathology and is more accessible for in vivo two photon imaging than medial prefrontal cortex $[53,54]$ (Fig. 1a).

We recorded spontaneous $\mathrm{Ca}^{2+}$ activity in the frame scan mode and found robust elevation in fluorescence indicating elevation in the intracellular $\mathrm{Ca}^{2+}$ concentrations (Fig. 1b, as an example). Somatic $\mathrm{Ca}^{2+}$ responses reflect spiking activity most likely mediated by opening of voltage-gated $\mathrm{Ca}^{2+}$ channels on the somata or diffusion of $\mathrm{Ca}^{2+}$ from nearby dendrites upon depolarization [60]. Since the goal of the study is to determine whether NMDAR modulators may affect in vivo neural activity in schizophrenia model mice, we first wanted to determine whether activation of NMDARs have significant contribution to the recorded $\mathrm{Ca}^{2+}$ signals. To do so, we tested the effect of selective NMDAR antagonists MK-801.

We found a significant reduction in the $\mathrm{Ca}^{2+}$ signals starting $30 \mathrm{~min}$ after MK-801 injection (i.p. $0.3 \mathrm{mg} / \mathrm{kg}$; Fig. $1 \mathrm{~b}$ and c; 84 somas $/ 3$ mice, $A m p=39.89 \pm 3.48 \%$; Total activity $=13.36 \pm 3.21 \%$; Freq $=21.14 \pm 4.38 \%$; all normalized to baseline (pre-MK-801) level (100\%); $P<$ 0.001). The significant reduction in $\mathrm{Ca}^{2+}$ responses indicated that NMDARs play a critical role in the observed $\mathrm{Ca}^{2+}$ responses. Previous studies have shown that MK801 injection resulted in a significant reduction in the burst spikes in the prefrontal neurons [61], suggesting that our $\mathrm{Ca}^{2+}$ responses could largely be mediated by burst spikes (see Discussion).

Previous works using in vivo single unit recording showed a reduction in spike rate in the putative inhibitory neurons and a concomitant increase in spike rate of excitatory neurons after systemic injection of MK-801 
[61, 62]. After i.p injection of MK-801 $(0.3 \mathrm{mg} / \mathrm{kg})$ in wild type mice, we found a reduction in spike rate in the fast-spiking neurons (likely inhibitory neurons) and an enhancement in firing rate in the regular spiking neurons (likely excitatory neurons) (Fig. 2a). A higher percentage of units showing reduction in burst spike (Fig. 2b, saline, 96 units/7mice; MK-801, 71 units/5mice, saline $=17.64 \%$, MK- $801=39.58 \%$ ) was seen with a significant increase in single spike frequency starting $30 \mathrm{~min}$ after MK-801 injection (Fig.2c, saline $=102.81 \pm 9.29 \%$, MK-801 $=126.50 \pm 9.37 \%$; unpaired t-test, $P<0.05)$. Taken together, our findings are consistent with previous studies regarding changes in spiking after administration of NMDAR blockers, and further suggest that the recorded $\mathrm{Ca}^{2+}$ signals most likely reflect burst spike rather than single spikes (see Discussion) [61, 63].

\section{Elevated neural activity in the frontal cortex of schizophrenia-like model mice}

After confirming that our methods (imaging and recording) can readily detect changes in neural activity caused by NMDAR blocker, and consistent with published results, we set to examine the impact of NMDAR modulators on neural activity in schizophrenia model. First, we examined whether the general activity level is altered in our schizophrenia model mice. Previous studies showed
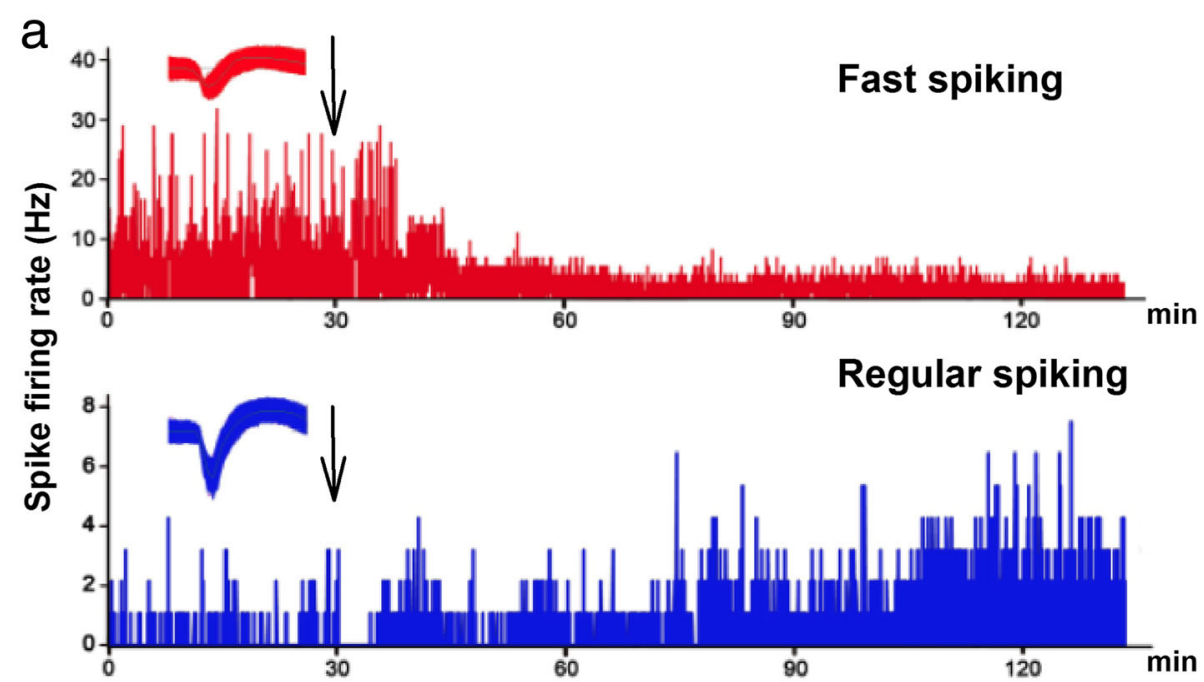

b

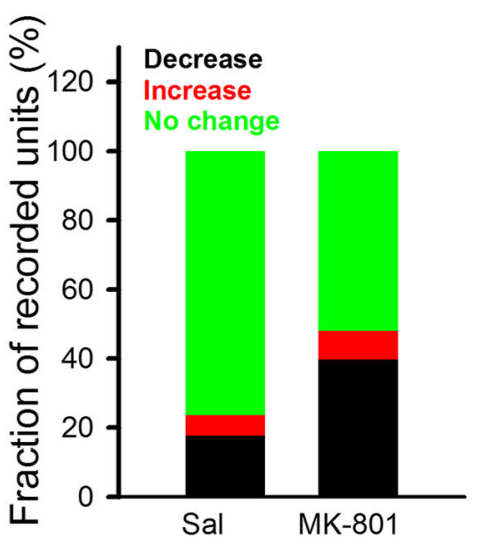

C

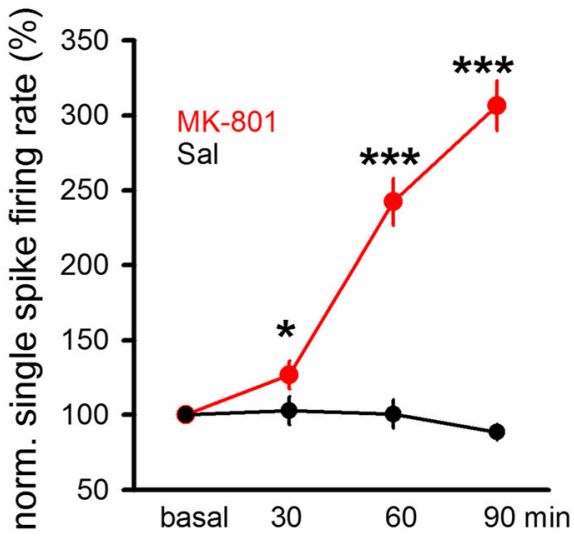

Fig. 2 In vivo recording demonstrated differential changes in neural activity after injection of MK-801. a Sample recording of in vivo single unit recording of neural activity in the mPFC (Upper). In a fast-spiking neuron (basal spike frequency > 10 spike/sec), injection (i.p) of MK-801 (0.3 mg/ $\mathrm{kg}$, arrow) led to a reduction in neural spiking over time. (Lower) In a regular spiking neuron, MK-801 injection led to an increase in neural activity over time. Sample spike waveforms were shown in the inserts. $\mathbf{b}$ Fraction of recorded units showing no change, increase and decrease in burst spike rate in the saline (Sal) and MK-801 injection group. Burst spike rate were not altered in most neurons in the Sal group, while nearly twice as many unit showed significant decrease in burst spike rate in the MK- 801 group. The group showing decrease represents the average burst firing rate following 30 to 60 min after administration of MK-801. Decrease is defined as reduced by $20 \%$ or more, increase defined as increase by $20 \%$ or over, and no change defined as values between 80 and 120\%, all compared to baseline. c Normalized changes in single spike rates before, 30 , 60 and 90 min after MK-801 injection. Significant increase was seen starting 30 min after MK-801 injection 
that injection of anti- Nrg1 antibodies led to the appearance of schizophrenia-like phenotypes in mice $[49,50]$, which is likely caused by elevated Nrg1 signaling [50]. In addition, enhanced synaptic transmission onto excitatory neurons was also seen in the anti-Nrg1 mice [49], consistent with other reports of hyperactivity in mice with NMDAR hypofunction in the inhibitory neurons [2]. Thus, we first examined in vivo cortical activity in the anti-Nrg1 mice.

In neurons expressing CAG-GCaMP6s, we found a significant increase in the spontaneous $\mathrm{Ca}^{2+}$ responses in anti-Nrg1 mice, compared to mice injected with antiRag antibodies (Fig. 3A1). This increase was seen in the amplitude and frequency of individual $\mathrm{Ca}^{2+}$ responses (Fig. 3A2). Total neural activity was quantified by integrating $\mathrm{Ca}^{2+}$ signals and a significant increase in the anti-Nrg1 mice was found (Fig. 3a; 113 somas/5 mice (Rag), 116 somas/6 mice (Nrg1); unpaired t-test, $P<$ 0.01 ), indicating an increase in neural activity. We further examined whether this increased neural activity occurred in the excitatory neurons by monitoring $\mathrm{Ca}^{2+}$ responses in neurons expressing CaMKII-GCaMP6s (Fig. 3B1). A significant increase in the amplitude and frequency of $\mathrm{Ca}^{2+}$ responses, and the total activity (Fig. 3B2\&3B3; Amp $=1.55 \pm 0.05$ (Rag), $1.78 \pm 0.05$ (Nrg1), unpaired t-test, $P<0.01$; Freq $=2.06 \pm 0.07$ (Rag), $2.55 \pm$ 0.08 (Nrg1), unpaired t-test, $P<0.001 ; 157$ somas $/ 4$ mice (Rag), 228 somas $/ 8$ mice (Nrg1), $\operatorname{Rag}=11.75 \pm 1.28$, $\mathrm{Nrg} 1=20.58 \pm 2.71$; unpaired t-test, $P<0.01$ ) was found, indicating elevated neuronal activity occurs in the excitatory neurons.

To confirm the above findings using an independent measurement, we recorded neural activity using in vivo single unit recording. We found a significant elevation in the mean firing rates (mostly single spikes) (Fig. 3C2; 88 units/3 mice (Rag), 78 units/3 mice (Nrg1); unpaired $\mathrm{t}$ test, $P<0.001$ ). Burst spike rate was not altered (Fig. 3C3; 41 units/3 mice (Rag); 55 units/3 mice (Nrg1)). Note the large increase in mean firing rate in the anti$\mathrm{Nrg} 1$ mice $(250 \%, \quad 8 \pm 2.10 \mathrm{~Hz} \quad$ (Rag), $20 \pm 3.57 \mathrm{~Hz}$ (Nrg1)). Thus, the elevated neural activity appears to be mostly associated with an increase in single spikes.

\section{D-cycloserine did not affect neuronal activity in the schizophrenia-like model mice}

As stated in the Introduction, although it has been shown that glycine/D-serine can effectively enhance synaptic NMDAR function/activity in mice [38, 39], a critical question regarding the in vivo efficacy of exogenous co-agonist is whether this enhanced NMDAR function necessarily translates into change in in vivo spiking activity. Since DCS/glycine/GlyT-1 inhibitors have shown certain efficacy in schizophrenia patients and model mice, we expected that they do so by modulating neural activity. We examined $\mathrm{Ca}^{2+}$ responses before and after injection of DCS $(30 \mathrm{mg} / \mathrm{kg}$, i.p). We have observed hyperlocomotion in the anti-Nrg1 mice which was not significantly affected by DCS injection (Additional file 1: Figure S1; 8 mice (Rag), 8 mice (Nrg1)). Compared to anti-Rag mice, no significant effect of DCS was found on spontaneous $\mathrm{Ca}^{2+}$ responses in anti-Nrg1 mice (Fig. 4a, b; raw data shown in Additional file 2: Figure S2), in neurons expressing either CAG-GCaMP6s (Fig. 4B1 \& Additional file 2: Figure S2; 77 somas/3 mice (Rag), 71 somas/4 mice (Nrg1)), Synapsin-GCaMP6s (Fig. 4B2; 83 somas/5 mice (Rag), 139 somas/4 mice (Nrg1)) or CaMKII- GCaMP6s virus (Fig. 4B3 \& Additional file 2: Figure S2 120 somas/4 mice (Rag), 129 somas/5 mice (Nrg1)). As shown in Additional file 2: Figure S2, the increased basal neuronal activity in anti-Nrg1 mice was still observed, consistent with the Fig. 3. This conclusion is further supported by the absence of changes in in vivo spike frequency after DCS injection in either anti-Nrg1 or anti-Rag mice, on either mean spike rate or burst spike rate (Fig. 4c; 3 mice (Rag), 3 (Nrg1)).

\section{Glycine transporter inhibition does not affect neural activity}

Previous evidence showed that endogenous glycine concentration can be effectively enhanced by inhibiting its uptake with GlyT-1 inhibitors [64, 65]. Numerous GlyT1 inhibitors with excellent drug-like properties have been tested in vivo [41, 66-69]. Here, we chose to use sarcosine which has been used widely in preclinical research [70, 71]. Two doses of sarcosine $(0.3 \mathrm{~g} / \mathrm{kg}$ and 1 $\mathrm{g} / \mathrm{kg}$, i.p) were used to examine $\mathrm{Ca}^{2+}$ responses in neurons expressing either synapsin-GCaMP6s (Fig. 5a, raw data shown in Additional file 3: Figure S3A) or CaMKIIGCaMP6s (Fig. 5b, raw data shown in Additional file 3: Figure S3B). We did not find any significant changes in $\mathrm{Ca}^{2+}$ responses, in either virus-infected neurons, for either dose, in either anti-Nrg1 or anti-Rag mice. These results suggest that enhancing the endogenous glycine level by inhibiting its uptake does not significantly alter neural activity.

In addition, we tested the effects of in vivo administration of glycine $(1.6 \mathrm{~g} / \mathrm{kg}$, i.p) [72, 73]. We found a large reduction in the movement of control (anti-Rag) mice in their home cages after injection with glycine (data not shown). When locomotion was analyzed in the open field, we did not find that glycine injection caused significant changes to locomotion in either anti-Nrg-1 or anti-Rag mice (Sup. Additional file 4 Figure S4A). In addition, a significant reduction in the spontaneous spiking was seen from in vivo recording in the home cage (Additional file 4: Figure S4B-C). Since brain activity level is influenced by the locomotion level in the freemoving mice we studied, this reduced locomotion may 
a1

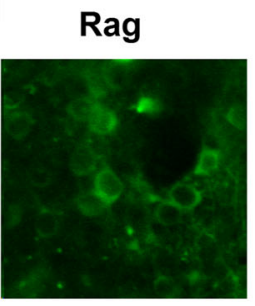

b1

Rag
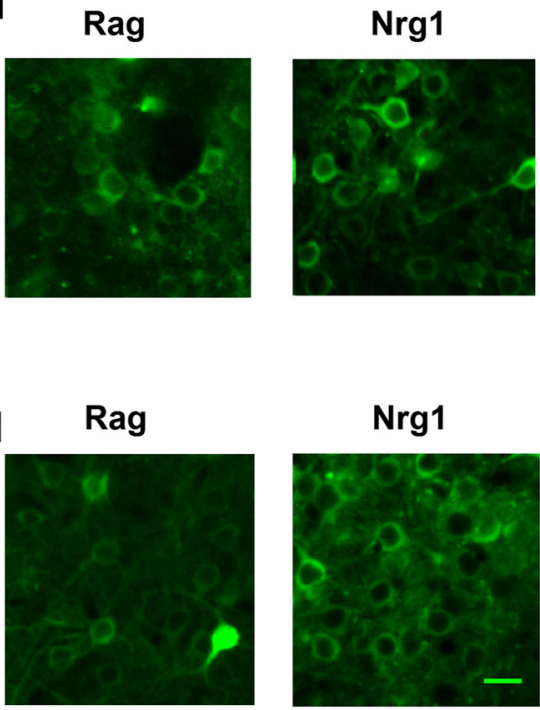

Nrg1

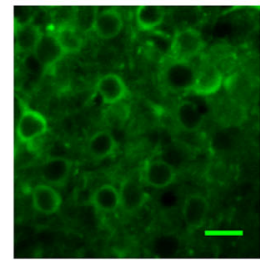

C1

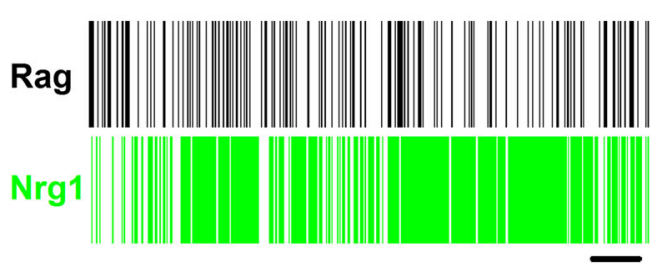

a2

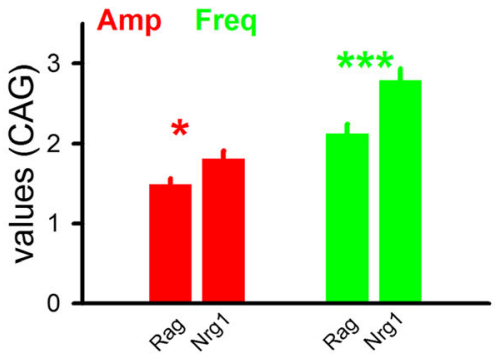

b2

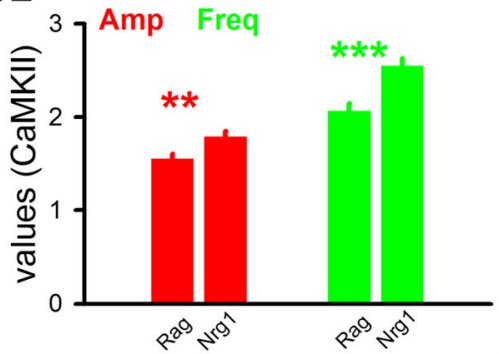

a3

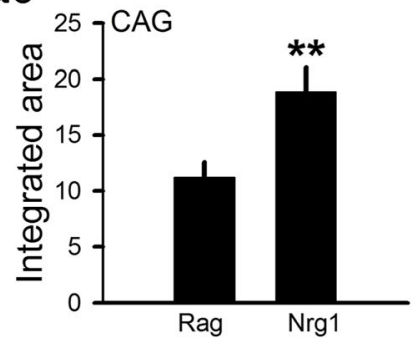

b3

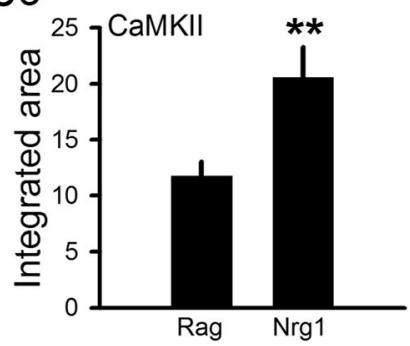

C3
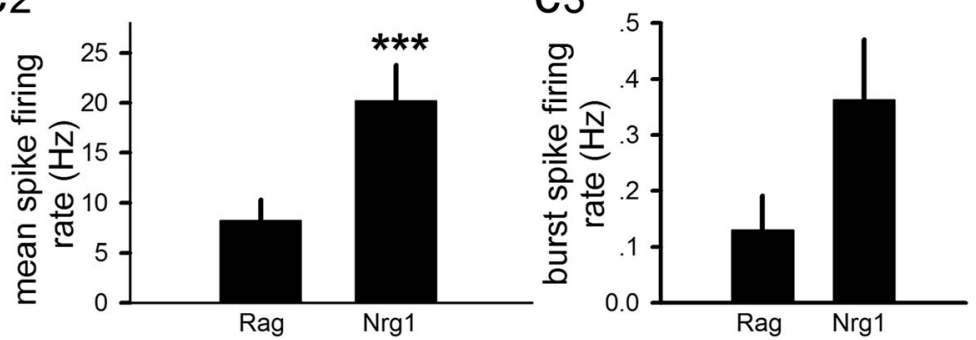

Fig. 3 Elevated basal neuronal activity in mice injected with anti-Nrg1 antibodies. a. Neural activity measured using CAG-GCaMP6s virus in FrA neurons. (A1) Sample images of neurons expressing CAG-GCaMP6s virus in the FrA, in mice injected with either anti-Rag antibody (left, Rag) or anti-Nrg1 antibody (right, Nrg1). (A2) Individual spontaneous $\mathrm{Ca}^{2+}$ response showed increase in amplitude (amplitude of $\Delta \mathrm{F} / \mathrm{F}$ ), and frequency (number of events per min), in mice injected with anti-Nrg1 antibodies. (A3) Total $\mathrm{Ca}^{2+}$ activity (integrated area of all events within 1 min) was also elevated in anti-Nrg1 mice. Scale bars, $10 \mu \mathrm{m}$. b. Neuronal activity in the excitatory neurons measured using CaMKIl-GCaMP6s virus in the FrA. (B1) Sample images of neurons expressing CaMKII-GCaMP6s virus in the anti-Rag (left) and anti-Nrg1 mice (right). (B2) Amplitude and frequency of individual spontaneous $\mathrm{Ca}^{2+}$ responses were significant higher in the anti-Nrg1 mice, compared to the anti-Rag mice. (B3) Total Ca ${ }^{2+}$ activity level was higher in the anti-Nrg1 mice compared to the anti-Rag control mice. Scale bars, $10 \mu \mathrm{m}$. c. In vivo single unit recording. (C1) Sample recording in an anti-Rag (upper) or anti-Nrg1 mouse (lower). Each vertical line represents a single spike. Scale bar, 50 s. (C2) Significantly higher mean spike rate was seen in the anti-Nrg1 mice, compared to the anti-Rag mice. (C3) Burst spike rate was not significantly different between the anti-Nrg1 and anti-Rag mice. ${ }^{*}, P<0.05 ;{ }^{* *}, P<0.01,{ }^{* * *}, P<0.001$

interfere with the interpretation of glycine effects on NMDAR-dependent modulation of brain activity. Thus, we did not examine the effect of glycine injection on in vivo neuronal activity any further.

\section{Discussion}

In this study, we addressed a simple question: does Dcycloserine or sarcosine alter neuronal spiking in the frontal cortex of schizophrenia-like model mice? By using combined in vivo two-photon time lapse $\mathrm{Ca}^{2+}$ imaging and in vivo single-unit recording, we found that spontaneous neuronal activity is significantly increased in schizophrenia-like model, but unaltered by administration of the above compounds, suggesting no major effects of the above NMDAR enhancers on neural spike activity in vivo in schizophrenia-like model mice.

\section{Technical considerations for what the signals represent}

The majority of neural spiking measured in this study, either directly using in vivo recording or inferred from $\mathrm{Ca}^{2+}$ responses, come from excitatory neurons, as reflected by sampling bias of the recording electrodes, spike width and frequency of the recorded spikes, and promoter used to express GCaMP6s. Neuronal activity measured using $\mathrm{Ca}^{2+}$ imaging showed a huge reduction after MK-801 injection, while burst spike rate decreased and single spike rate significantly increased as measured using in vivo recording (Figs. 1, 2). Based on the 


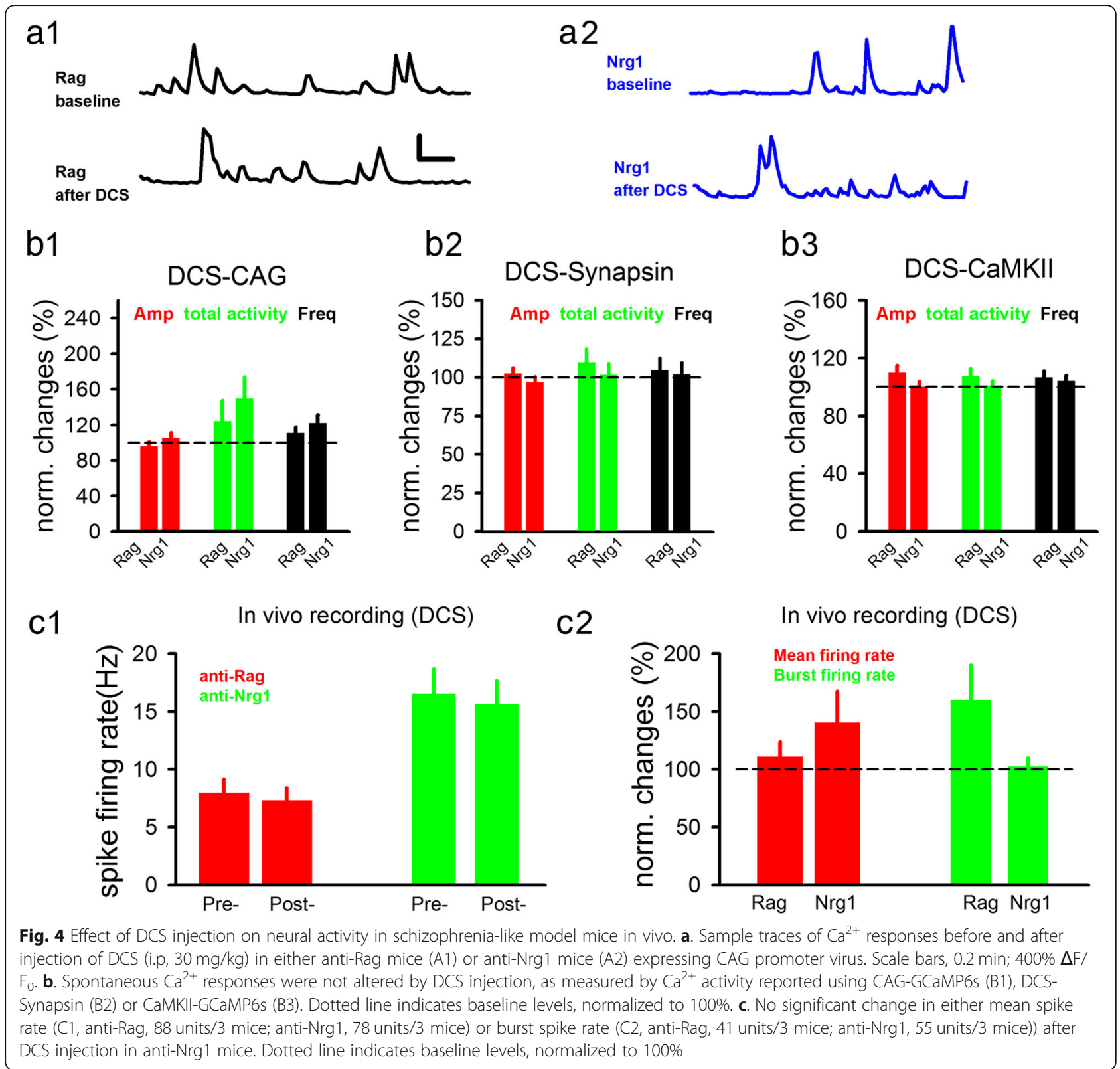

comparison between $\mathrm{Ca}^{2+}$ imaging and in vivo recording, the $\mathrm{Ca}^{2+}$ activity we observed in the frontal neurons are likely mediated by burst spikes in neurons. This conclusion is consistent with the sensitivity of GCaMP6s shown in previous studies [63]. This technical aspect is important since it indicates that $\mathrm{Ca}^{2+}$ signals in our results mostly reflect synaptic inputs rather than random spiking of neurons (we imaged cell somas under resting/ no stimulation condition), and hence more likely reflect changes in input-driven functions of these neurons. From in vivo recordings, we also obtained information on the spontaneous spiking (mostly single spikes), which likely reflects random spiking rather than input-driven neuronal activity. Random spiking could in some ways be viewed as noise rather than signals, or signals reflecting the internal state. Due to the high spike rate there is a possibility that some spikes occur close enough to each other temporally to trigger significant $\mathrm{Ca}^{2+}$ responses (i.e., they appear as burst spikes).

\section{Changes of neural activity in schizophrenia-like model mice}

Previous works showed that administration of anti-Nrg1 antibodies induced schizophrenia-like behavioral phenotypes (including hyper-locomotion and impaired prepulse inhibition of startle) and altered synaptic transmission in adult mice $[49,50]$. Compared to the more established models of schizophrenia in the literature, being 

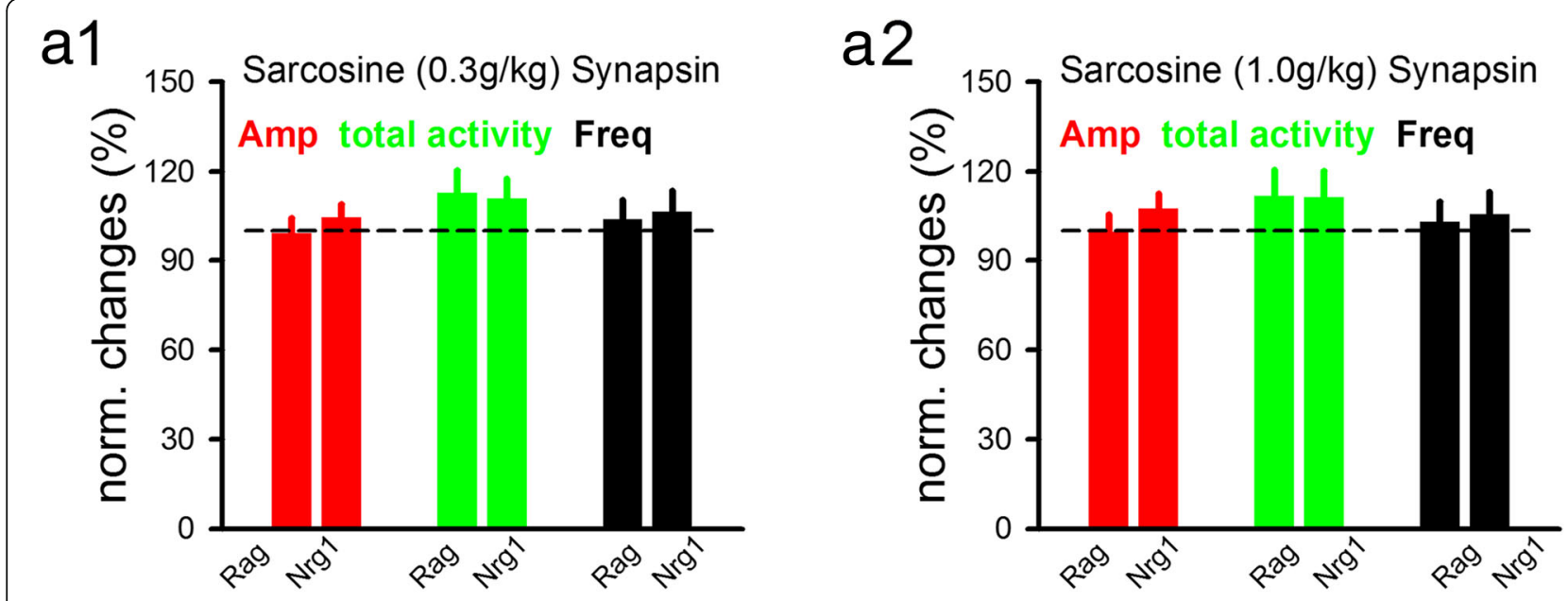

\section{b1}

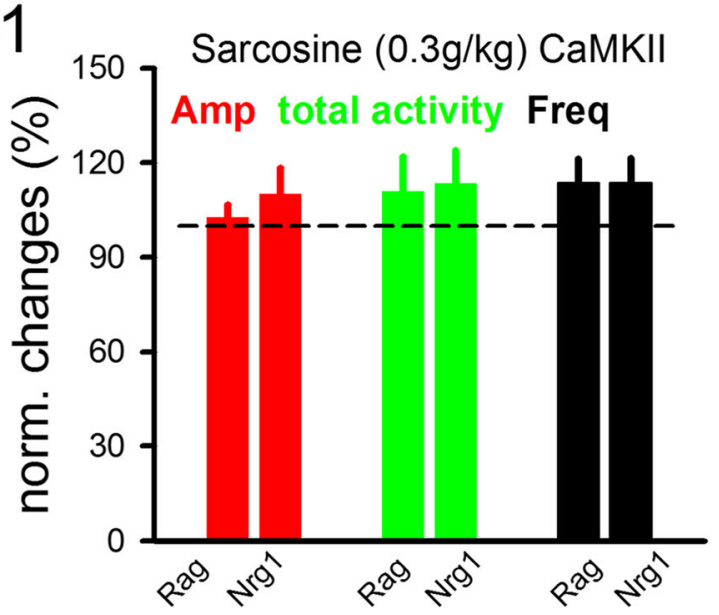

b2

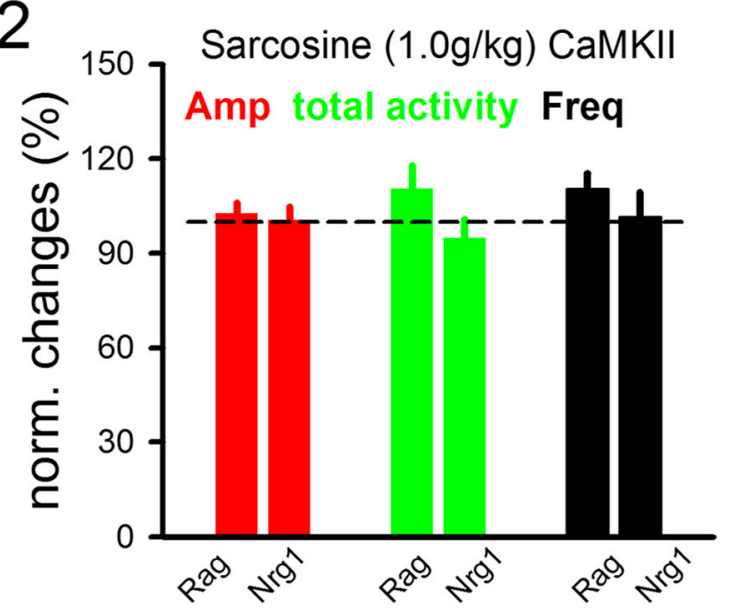

Fig. 5 Effect of sarcosine on neural activity schizophrenia-like model mice. a. In neurons expressing synapsin-GCaMP6s virus, i. p. injection of sarcosine (A1; 0.3 g/kg; Rag, 104 somas/5 mice; Nrg1, 119 somas/4 mice) (A2; 1 g/kg; Rag, 94 somas/5 mice; Nrg1, 124 somas/4 mice) did not significantly change the amplitude, frequency or total activity of spontaneous $\mathrm{Ca}^{2+}$ responses, in either anti-Nrg1 or anti-Rag mice. Dotted line indicates baseline levels, normalized to 100\%. b. In neurons expressing CaMKIl-GCaMP6s virus, injection sarcosine (B1; 0.3 g/kg; Rag, 116 somas/4 mice; Nrg1, 60 somas/3 mice) (B2; 1 g/kg; Rag, 124 somas $/ 5$ mice; Nrg1, 85 somas/5 mice) did not significantly change the amplitude, frequency or total activity of $\mathrm{Ca}^{2+}$ responses, in either anti-Nrg1 or anti-Rag mice. Dotted line indicates baseline levels, normalized to 100\%

genetic, pharmacological or lesion, our model of using anti-Nrg1 antibodies is fairly new and less established, regarding the characterization of behavioral phenotypes, pathophysiology, responses to drugs/treatment (such as antipsychotics) and the developmental time course of the landmark events. On other hand, one major advantage of our model is that the onset of schizophrenia can be controlled by the timing of antibody injection so that this is one of rare model to study late/adult onset schizophrenia (Ju et al., 2019).

Consistent with prior studies showing hyperactivity in schizophrenia-like models [74, 75], we found elevated in vivo activity, both in $\mathrm{Ca}^{2+}$ response and single spike rate. The increase in total activity revealed by $\mathrm{Ca}^{2+}$ responses is rather small (Fig. 3A3 \& B3), but the increase in in vivo spike rate is fairly large (Fig. 3c). These differences are consistent with the majority of $\mathrm{Ca}^{2+}$ responses mediated by burst spikes, and also indicate that increase in single spike (random spiking) is a major electrophysiological alteration in schizophrenia-like models.

We found that injection of MK-801 led to an initial reduction in the spiking of presumed fast-spiking neurons followed by delayed increased spiking in the presumed excitatory neurons in the $\mathrm{mPFC}$, consistent with those from previous studies $[61,62]$. These results are also consistent with increased activity in anterior cingulate cortex in an acute MK-801 treatment model of schizophrenia using two-photon imaging [76]. Intriguingly, Ranson (2019) 
reported reduced activity in excitatory neurons in V1 in the same model. This reduction may be explained by suppression of V1 activity by anterior cingulate cortex inputs in this model, or regional differences in the distribution of NMDARs. It was well established that the distribution of NMDAR subunits is very strongly dependent on the specific brain regions [8].

In addition to the general level of neural activity, it is widely accepted that the synchronization of neural spiking either in the same brain region or between different brain regions is significantly altered in schizophrenia patients and mice [77-80]. Altered gamma oscillations have been reported, together with deficits in working memory [81-83]. Hippocampal-prefrontal synchrony during working memory task is impaired in a schizophrenia model [84], and deficits in frontal cortical gamma-band synchrony may contribute to the impaired cognitive control in schizophrenia [85]. Our current dataset does not have sufficient temporal resolution to perform such an analysis, but exploring whether synchrony of spiking is altered in our model mice and the potential impact of NMDAR modulators is of interest and importance in future studies.

\section{Potential explanations for the lack of effectiveness of NMDAR co-agonists on neuronal activity}

There are a few potential possibilities for why this approach did not alter in vivo neuronal activity in schizophrenia-like model mice in this study: (1) Hypofunction of NMDARs in schizophrenia, especially the hypofunction of NMDARs on the inhibitory neurons $[86,87]$, which is supported by from both postmortem findings and preclinical studies using mice with reduced NMDAR expression in the inhibitory neurons [88-90]. However, if the density of NMDAR in inhibitory neurons is so low that the enhancement provided with NMDAR co-agonists may not be sufficient to increase spiking. This scenario is consistent with prior findings of enhanced synaptic NMDAR function by these modulators $[11,38,65]$ but no impact on spiking in this study. Furthermore, the loss of inhibitory neurons reported in schizophrenia patients and model animals may have additional contribution to this lack of efficacy in increasing neuronal spiking [91-95]. In our schizophrenia-like model mice, it is unclear whether cell loss and NMDAR hypofunction occurs, although there is evidence for reduced NMDAR activation by NRG1 stimulation in the PFC of both human schizophrenia patients and rodent models $[96,97]$. In the future studies, it is necessary to confirm the NMDAR hypofunction and cell loss in our model. (2) Saturation of the strychnine-insensitive glycine binding site on NMDARs of the co-agonists. To boost NMDAR activation by coagonists, the binding sites need not to be saturated. Our results suggest that the binding sites might be saturated, consistent with prior in vivo study [98], although there are some evidence indicating the glycine binding site not saturated [40, 41]. However, whether the binding site is saturated needs to be determined in vivo since microenvironment might be altered in the brain slices [99]. Furthermore, whether glycine site is saturated in the schizophrenia brain is unknown. Since we only examined in vivo neuronal activity in the frontal neurons, it remains to be tested whether NMDAR co-agonists can boost neuronal activity in other brain regions in schizophrenia-like model mice. (3) It is possible that the drug doses we used are not adequate to reverse hyperactivity in schizophrenia-like model. Doses were selected based on prior studies which haven shown efficacy in schizophrenia-like models. For example, DCS at $30 \mathrm{mg} / \mathrm{kg}$ was shown to be efficacious in animals and patients [100-102], and sarcosine at the doses we used improved the schizophrenia-like phenotypes in rodents [70, 71]. It thus unlikely that dose was a major contributing factor to the lack of efficacy. (4) Our schizophrenia model was induced in the adult and has certain distinct alterations than the typical developmental or genetic model of schizophrenia (Ju et al., 2019). Thus, it remains to be tested whether these NMDAR modulators have significant impact on neural activity in developmental model of schizophrenia.

In addition to the co-agonist strategy used in this and other works, an array of direct NMDAR enhancers have been generated and tested. The more interesting and potentially useful ones are the positive allosteric modulators of NMDARs (NMDAR-PAMs) [103-105]. These PAMs include UBP compound with different subunit-selective properties $[105,106]$, and series of subunit-selective PAMs from Genentech [107, 108]. One of the NMDAR-PAMs, GNE-8324, showed selective potentiation of NMDAR synaptic responses in the inhibitory neurons [108]. Use of allosteric NMDAR enhancers can avoid some of the issues or uncertainty faced by NMDAR co-agonists, such as specific subcellular locations of NMDARs [109] and binding site saturation. In addition, since some PAMs show much higher potency in enhancing NMDAR responses, they may also be able to overcome the potential issue of reduced density of NMDAR or inhibitory neurons in the schizophrenia brains as discussed above. Thus, we suggest their effects in schizophrenia is worthy of testing.

\section{Conclusions}

We failed to find significant impact of NMDAR modulators DCS and sarcosine on neural spiking in vivo in both schizophrenia-like model and wild type mice. This finding is consistent with the lack of efficacy of these modulators in some human clinical trials. We have discussed possible reasons for this strategy not to be effective in enhancing neuronal spiking and suggest that allosteric enhancers of NMADRs might avoid some of the potential issues and are worthy of testing. 


\section{Supplementary information}

Supplementary information accompanies this paper at https://doi.org/10. 1186/s12888-019-2306-1

Additional file 1 Figure S1. Effect of DCS on locomotion in the open field test. Hyperlocomotion was seen in anti-Nrg1 mice, which was not affected by injection of DCS (bar). 8 mice (Rag), 8 mice (Nrg1).

Additional file 2 Figure S2. Effect of DCS injection on neural activity in schizophrenia-like model mice in vivo. These data were the raw data obtained in the same experiments as those in Fig. 4. Amplitude, frequency or integrated area of spontaneous $\mathrm{Ca}^{2+}$ responses were shown before and after DCS injection, measured using CAG-GCaMP6s or CaMKII-GCaMP6s. A. Higher neuronal activity was observed in the anti-Nrg1 group but no effect of DCS, measured by the amplitude of $\mathrm{Ca}^{2+}$ responses. For CAG-GCaMP6s, basal activity, Rag vs. Nrg1, $F_{1,292}=16.21, P<0.05$; with DCS, Rag vs. Nrg1, $F_{1,292}=16.21, P<0.001$. For CaMKII-GCaMP6s, basal activity, Rag vs. Nrg1, $F_{1,494}=7.163, P<0.01$ ). B. Higher neuronal activity was observed in the anti-Nrg1 group but no effect of DCS, measured by the frequency of $\mathrm{Ca}^{2+}$ responses. For CAG-GCaMP6s, with DCS, Rag vs. Nrg1, $F_{1,292}=11.01, P<0.01$. For CaMKII-GCaMP6s, basal activity, Rag vs. Nrg1, $F_{1,494}=5.22, P<0.01$. C. Higher neuronal activity was observed in the anti-Nrg1 group but no effect of DCS, measured by the total activity of $\mathrm{Ca}^{2+}$ responses. For CAG-GCaMP6s, basal activity, Rag vs. Nrg1, $\mathrm{F}_{1,2} 292=22.71$, $P<0.001$; with DCS, Rag vs. Nrg1, $F_{1,292}=22.71, P<0.01$. For CaMKII-GCaMP6s, basal activity, Rag vs. Nrg1, $F_{1,494}=5.22, P<0.05$; with DCS, Rag vs. Nrg1, $F_{1}$, $494=5.22, P<0.05$.

Additional file $\mathbf{3}$ Figure $\mathbf{S 3}$. Sarcosine does not affect neural activity in schizophrenia-like model mice. These data were the raw data obtained in the same experiments as those in Fig. 5. Amplitude, frequency or integrated area of spontaneous $\mathrm{Ca}^{2+}$ responses were shown before and after sarcosine injection, measured using Synapsin-GCaMP6s (A), or CaMKIIGCaMP6s (B). A. In neurons expressing synapsin-GCaMP6s virus, injection of $0.3 \mathrm{~g} / \mathrm{kg}$ or $1 \mathrm{~g} / \mathrm{kg}$ sarcosine did not significantly change the amplitude (A1), frequency (A2) or total activity (A3) of spontaneous $\mathrm{Ca}^{2+}$ responses, in either anti-Nrg1 or anti-Rag mice. Increased basal neural activity was observed in the anti-Nrg1 group. A1. $0.3 \mathrm{~g} / \mathrm{kg}$, basal activity, Rag vs. Nrg1, $F_{1,442}=43.78, P<0.001$; with sarcosine, anti-Rag vs. anti-Nrg1, $F_{1,442}=$ 43.78, $P<0.001$. A2. $0.3 \mathrm{~g} / \mathrm{kg}$, basal activity, anti-Rag vs. anti-Nrg1, $F_{1,442}=$ 32.48, $P<0.001$; with sarcosine, anti-Rag vs. anti-Nrg1, $F_{1,442}=32.48, P<$ $0.001 .1 .0 \mathrm{~g} / \mathrm{kg}$, basal activity, anti-Rag vs. anti-Nrg1, $F_{1,432}=15.62, P<$ 0.05; with sarcosine, anti-Rag vs. anti-Nrg1, $F_{1,442}=15.62, P<0.01$. A3. 0.3 $\mathrm{g} / \mathrm{kg}$, basal activity, anti-Rag vs. anti-Nrg1, $F_{1,442}=41.34, P<0.001$; with sarcosine, anti-Rag vs. anti-Nrg1, $F_{1,442}=41.34, P<0.001$. B. In neurons expressing CaMKII-GCaMP6s virus, injection of $0.3 \mathrm{~g} / \mathrm{kg}$ or $1 \mathrm{~g} / \mathrm{kg}$ sarcosine did not significantly alter the amplitude (B1), frequency (B2) or total activity (B3) of $\mathrm{Ca}^{2+}$ responses, in either anti-Nrg1 or anti-Rag mice. Increased neuronal activity was observed in the anti-Nrg1 group. B1. $1.0 \mathrm{~g} / \mathrm{kg}$, basal activity, anti-Rag vs. anti-Nrg1, $F_{1,414}=17.24, P<0.01$; with sarcosine, antiRag vs. anti-Nrg1, $F_{1,414}=17.24, P<0.01$. B2. $0.3 \mathrm{~g} / \mathrm{kg}$, basal activity, antiRag vs. anti-Nrg1, $F_{1,348}=7.054, P<0.05$. B3. $1.0 \mathrm{~g} / \mathrm{kg}$, basal activity, antiRag vs. anti-Nrg1, $F_{1,414}=4.78, P<0.05$

Additional file 4 Figure S4. Effect of glycine on locomotion in the open field test and in vivo neuronal spike rate. A. Anti-Nrg1 mice showed hyperlocomotion compared to anti-Rag group. Glycine injection did not significantly alter locomotion in either anti-Rag or anti Nrg1 mice. 8 mice (Rag), 8 mice (Nrg1). B. Mean spike rate showed large reduction after glycine injection in both anti-Rag and anti-Nrg1 group (paired t-test, $P<0.001$ ). C. Burst spike rate was not significantly altered by glycine injection.

\section{Abbreviations}

anti-Nrg1: Anti-Neuregulin 1; anti-Rag: Anti-Ragweed; DCS: D-cycloserine; FrA: Frontal association cortex; GlyT-1: Glycine transporter 1; mPFC: Medial prefrontal cortex; NMDAR: N-methyl-D-aspartate receptor; NRG1: Neuregulin1

\section{Acknowledgments}

We thank Professor Wenbiao Gan's lab for their help and CAG-GCaMP6s virus.

\section{Authors' contributions}

$L Y$, experiment design, data collection and analysis, discussion and writing; ZW, experiment design, data collection and analysis and discussion; DD, experiment design, data collection, discussion; RY, experiment design, data collection and writing; JJ, data collection; QZ, experiment design, discussion and writing. All authors read and approved the final manuscript.

\section{Funding}

This work was supported by grants from Shenzhen Science and Technology Innovation Funds (KQTD2015032709315529 and JCYJ20170412150845848). The funder played no role in study design, data collection, analysis, interpretation of data, and in writing the manuscript.

\section{Availability of data and materials}

The datasets used and/or analyzed during the current study are available from the corresponding author on reasonable request.

\section{Ethics approval and consent to participate}

All animal experiments have approved by the Peking University Shenzhen Graduate School Animal Care and Use Committee and were in accordance with the ARRIVE guidelines on the Care and Use of Experimental Animals.

\section{Consent for publication}

Not applicable.

\section{Competing interests}

The authors declare that they have no competing interests.

Received: 17 April 2019 Accepted: 30 September 2019

Published online: 25 October 2019

\section{References}

1. Lewis DA, Hashimoto T, Volk DW. Cortical inhibitory neurons and schizophrenia. Nat Rev Neurosci. 2005;6(4):312-24.

2. Nakazawa K, Zsiros V, Jiang Z, Nakao K, Kolata S, Zhang S, Belforte JE. GABAergic interneuron origin of schizophrenia pathophysiology. Neuropharmacology. 2012;62(3):1574-83.

3. Cohen SM, Tsien RW, Goff DC, Halassa MM. The impact of NMDA receptor hypofunction on GABAergic neurons in the pathophysiology of schizophrenia. Schizophr Res. 2015;167(1-3):98-107.

4. Lewis DA, Moghaddam B. Cognitive dysfunction in schizophrenia: convergence of gamma-aminobutyric acid and glutamate alterations. Arch Neurol. 2006;63(10):1372-6.

5. Coyle JT. Glutamate and schizophrenia: beyond the dopamine hypothesis Cell Mol Neurobiol. 2006;26(4-6):365-84.

6. Olney JW, Farber NB. Glutamate receptor dysfunction and schizophrenia. Arch Gen Psychiatry. 1995;52(12):998-1007.

7. Zhou Q, Sheng M. NMDA receptors in nervous system diseases. Neuropharmacology. 2013;74:69-75.

8. Paoletti $\mathrm{P}$, Bellone $\mathrm{C}$, Zhou Q. NMDA receptor subunit diversity: impact on receptor properties, synaptic plasticity and disease. Nat Rev Neurosci. 2013; 14(6):383-400.

9. Traynelis SF, Wollmuth LP, McBain CJ, Menniti FS, Vance KM, Ogden KK, Hansen KB, Yuan H, Myers SJ, Dingledine R. Glutamate receptor ion channels: structure, regulation, and function. Pharmacol Rev. 2010;62(3):405-96.

10. Wolosker H. NMDA receptor regulation by D-serine: new findings and perspectives. Mol Neurobiol. 2007;36(2):152-64.

11. Thomson AM, Walker VE, Flynn DM. Glycine enhances NMDA-receptor mediated synaptic potentials in neocortical slices. Nature. 1989;338(6214):422-4.

12. Lakhan SE, Caro M, Hadzimichalis N. NMDA receptor activity in neuropsychiatric disorders. Front Psychiatry. 2013;4:52.

13. Balu DT. The NMDA receptor and schizophrenia: from pathophysiology to treatment. Adv Pharmacol. 2016;76:351-82.

14. Aleman A, Lincoln TM, Bruggeman R, Melle I, Arends J, Arango C, Knegtering $\mathrm{H}$. Treatment of negative symptoms: where do we stand, and where do we go? Schizophr Res. 2017;186:55-62.

15. Hashimoto K, Fukushima T, Shimizu E, Komatsu N, Watanabe H, Shinoda N, Nakazato M, Kumakiri C, Okada S, Hasegawa H, et al. Decreased serum levels of D-serine in patients with schizophrenia - evidence in support of the $\mathrm{N}$ methyl-D-aspartate receptor hypofunction hypothesis of schizophrenia. Arch Gen Psychiatry. 2003;60(6):572-6. 
16. Hashimoto K, Engberg G, Shimizu E, Nordin C, Lindstrom LH, lyo M. Reduced D-serine to total serine ratio in the cerebrospinal fluid of drug naive schizophrenic patients. Prog Neuro-Psychopharmacol Biol Psychiatry. 2005:29(5):767-9.

17. Bendikov I, Nadri C, Amar S, Panizzutti R, De Miranda J, Wolosker H, Agam G. A CSF and postmortem brain study of D-serine metabolic parameters in schizophrenia. Schizophr Res. 2007;90(1-3):41-51.

18. Sumiyoshi T, Anil AE, Jin D, Jayathilake K, Lee M, Meltzer HY. Plasma glycine and serine levels in schizophrenia compared to normal controls and major depression: relation to negative symptoms. Int J Neuropsychopharmacol. 2004;7(1):1-8.

19. Forsyth JK, Bachman P, Mathalon DH, Roach BJ, Asarnow RF. Augmenting NMDA receptor signaling boosts experience-dependent neuroplasticity in the adult human brain. Proc Natl Acad Sci U S A. 2015;112(50):15331-6.

20. Kantrowitz JT, Woods SW, Petkova E, Cornblatt B, Corcoran CM, Chen HH, Silipo G, Javitt DC. D-serine for the treatment of negative symptoms in individuals at clinical high risk of schizophrenia: a pilot, double-blind, placebo-controlled, randomised parallel group mechanistic proof-ofconcept trial. Lancet Psychiatry. 2015;2(5):403-12.

21. Lane HY, Chang YC, Liu YC, Chiu CC, Tsai GE. Sarcosine or D-serine add-on treatment for acute exacerbation of schizophrenia: a randomized, doubleblind, placebo-controlled study. Arch Gen Psychiatry. 2005;62(11):1196-204.

22. Buchanan RW, Freedman R, Javitt DC, Abi-Dargham A, Lieberman JA. Recent advances in the development of novel pharmacological agents for the treatment of cognitive impairments in schizophrenia. Schizophr Bull. 2007; 33(5):1120-30.

23. Iwata Y, Nakajima S, Suzuki T, Keefe RSE, Plitman E, Chung JK, Caravaggio F, Mimura M, Graff-Guerrero A, Uchida H. Effects of glutamate positive modulators on cognitive deficits in schizophrenia: a systematic review and meta-analysis of double-blind randomized controlled trials. Mol Psychiatry. 2015;20(10):1151-60

24. Fusar-Poli P, Papanastasiou E, Stahl D, Rocchetti M, Carpenter W, Shergill S, McGuire P. Treatments of negative symptoms in schizophrenia: metaanalysis of 168 randomized placebo-controlled trials. Schizophr Bull. 2015; 41(4):892-9.

25. Sarkar S, Hillner K, Velligan DI. Conceptualization and treatment of negative symptoms in schizophrenia. World J Psychiatry. 2015;5(4):352-61.

26. Buchanan RW, Javitt DC, Marder SR, Schooler NR, Gold JM, McMahon RP, Heresco-Levy U, Carpenter WT. The cognitive and negative symptoms in schizophrenia trial (CONSIST): the efficacy of glutamatergic agents for negative symptoms and cognitive impairments. Am J Psychiatry. 2007; 164(10):1593-602.

27. Harvey RJ, Yee BK. Glycine transporters as novel therapeutic targets in schizophrenia, alcohol dependence and pain. Nat Rev Drug Discov. 2013; 12(11):866-85

28. Javitt DC. Glycine transport inhibitors and the treatment of schizophrenia. Biol Psychiatry. 2008;63(1):6-8.

29. Hashimoto K. Glycine transporter inhibitors as therapeutic agents for schizophrenia. Recent Pat CNS Drug Discov. 2006;1(1):43-53.

30. Zafra F, Aragon C, Olivares L, Danbolt NC, Gimenez C, Stormmathisen J. Glycine transporters are differentially expressed among Cns cells. J Neurosci. 1995;15(5):3952-69.

31. Cubelos B, Gimenez C, Zafra F. Localization of the GLYT1 glycine transporter at glutamatergic synapses in the rat brain. Cereb Cortex. 2005;15(4):448-59.

32. Betz H, Gomeza J, Armsen W, Scholze P, Eulenburg V. Glycine transporters: essential regulators of synaptic transmission. Biochem Soc Trans. 2006;34:55-8.

33. Tsai GC, Lane HY, Yang PC, Chong MY, Lange N. Glycine transporter I inhibitor, N-methylglycine (Sarcosine), added to antipsychotics for the treatment of schizophrenia. Biol Psychiatry. 2004;55(5):452-6.

34. Dunayevich E, Buchanan R, Chen CY, Dietrich J, Sun H, Marder S. Efficacy and safety of the glycine transporter Type-1 inhibitor AMG 747 for the treatment of negative symptoms associated with schizophrenia. Neuropsychopharmacology. 2015;40:S206-7.

35. Balu DT, Coyle JT. The NMDA receptor 'glycine modulatory site' in schizophrenia: D-serine, glycine, and beyond. Curr Opin Pharmacol. 2015;20: 109-15.

36. Kingwell K. Schizophrenia drug gets negative results for negative symptoms. Nat Rev Drug Discov. 2014;13(4):244-5.

37. Johnson JW, Ascher P. Glycine potentiates the Nmda response in cultured mouse-brain neurons. Nature. 1987;325(6104):529-31.
38. Fadda E, Danysz W, Wroblewski JT, Costa E. Glycine and D-serine increase the affinity of N-methyl-D-aspartate sensitive glutamate binding-sites in ratbrain synaptic-membranes. Neuropharmacology. 1988;27(11):1183-5.

39. Mothet JP, Parent AT, Wolosker H, Brady RO, Linden DJ, Ferris CD, Rogawski MA, Snyder SH. D-serine is an endogenous ligand for the glycine site of the Nmethyl-D-aspartate receptor. Proc Natl Acad Sci U S A. 2000;97(9):4926-31.

40. Chen L, Muhlhauser M, Yang CR. Glycine tranporter-1 blockade potentiates NMDA-mediated responses in rat prefrontal cortical neurons in vitro and in vivo. J Neurophysiol. 2003;89(2):691-703.

41. Kinney GG, Sur C, Burno M, Mallorga PJ, Williams JB, Figueroa DJ, Wittmann M, Lemaire W, Conn PJ. The glycine transporter type 1 inhibitor N-[3-(4'fluorophenyl)-3-(4'-phenylphenoxy)propyl] sarcosine potentiates NMDA receptor-mediated responses in vivo and produces an antipsychotic profile in rodent behavior. J Neurosci. 2003;23(20):7586-91.

42. Tauck DL, Ashbeck GA. Glycine synergistically potentiates the enhancement of Ltp induced by a sulfhydryl reducing agent. Brain Res. 1990;519(1-2):129-32.

43. Watanabe $Y$, Saito H, Abe K. Effects of Glycine and structurally related amino-acids on generation of long-term potentiation in rat hippocampal slices. Eur J Pharmacol. 1992;223(2-3):179-84.

44. Mei L, Xiong WC. Neuregulin 1 in neural development, synaptic plasticity and schizophrenia. Nat Rev Neurosci. 2008;9(6):437-52.

45. Stefansson H, Sigurdsson E, Steinthorsdottir V, Bjornsdottir S, Sigmundsson T, Ghosh S, Brynjolfsson J, Gunnarsdottir S, Ivarsson O, Chou TT, et al. Neuregulin 1 and susceptibility to schizophrenia. Am J Hum Genet. 2002; 71(4):877-92.

46. Walsh T, McClellan JM, McCarthy SE, Addington AM, Pierce SB, Cooper GM, Nord AS, Kusenda M, Malhotra D, Bhandari A, et al. Rare structural variants disrupt multiple genes in neurodevelopmental pathways in schizophrenia. Science. 2008;320(5875):539-43.

47. Bertram I, Bernstein HG, Lendeckel U, Bukowska A, Dobrowolny H, Keilhoff G, Kanakis D, Mawrin C, Bielau H, Falkai P, et al. Immunohistochemical evidence for impaired neuregulin-1 signaling in the prefrontal cortex in schizophrenia and in unipolar depression. Ann N Y Acad Sci. 2007;1096:147-56.

48. Chong VZ, Thompson M, Beltaifa S, Webster MJ, Law AJ, Weickert CS. Elevated neuregulin-1 and ErbB4 protein in the prefrontal cortex of schizophrenic patients. Schizophr Res. 2008;100(1-3):270-80.

49. Ju J, Liu LP, Zhang YJ, Zhou Q. Effect of age onset on schizophrenia-like phenotypes and underlying mechanisms in model mice. Prog NeuroPsychopharmacol Biol Psychiatry. 2019;89:465-74.

50. Dominguez SL, Hegde GV, Hanson JE, Xiang H, Mandikian D, Boswell CA, Chiu C, Wu Y, Tsai SP, Fleck D, et al. Antibody-mediated stabilization of NRG1 induces behavioral and electrophysiological alterations in adult mice. Sci Rep. 2018;8:8239-51.

51. Yin DM, Chen YJ, Lu YS, Bean JC, Sathyamurthy A, Shen C, Liu X, Lin TW, Smith CA, Xiong WC, et al. Reversal of behavioral deficits and synaptic dysfunction in mice overexpressing neuregulin 1. Neuron. 2013;78(4):644-57.

52. Howard R, Rabins PV, Seeman MV, Jeste DV. Late-onset schizophrenia and verylate-onset schizophrenia-like psychosis: an international consensus. The international late-onset schizophrenia group. Am J Psychiatry. 2000;157(2):172-8.

53. Lai CSW, Franke TF, Gan WB. Opposite effects of fear conditioning and extinction on dendritic spine remodelling. Nature. 2012;483(7387):87-U130.

54. Maruff P, Wood SJ, Velakoulis D, Smith DJ, Soulsby B, Suckling J, Bullmore ET, Pantelis C. Reduced volume of parietal and frontal association areas in patients with schizophrenia characterized by passivity delusions. Psychol Med. 2005;35(6):783-9.

55. Bai Y, Li M, Zhou YM, Ma L, Qiao Q, Hu WL, Li W, Wills ZP, Gan WB. Abnormal dendritic calcium activity and synaptic depotentiation occur early in a mouse model of Alzheimer's disease. Mol Neurodegener. 2017;12:86100.

56. Baran H, Gramer M, Loscher W. Alterations in plasma and brain amino acids after administration of the glycine/NMDA receptor partial agonist, Dcycloserine, to mice and rats. Eur J Pharmacol. 1995;273(1-2):197-201.

57. Amiaz R, Kent I, Rubinstein K, Sela BA, Javitt D, Weiser M. Safety, tolerability and pharmacokinetics of open label sarcosine added on to anti-psychotic treatment in schizophrenia - preliminary study. Isr J Psychiatry Relat Sci. 2015:52(1):12-5.

58. Gobert A, Rivet JM, Billiras R, Parsons F, Millan MJ. Simultaneous quantification of D- vs. L-serine, taurine, kynurenate, phosphoethanolamine and diverse amino acids in frontocortical dialysates of freely-moving rats: differential modulation by N-methyl-D-aspartate (NMDA) and other pharmacological agents. J Neurosci Methods. 2011;202(2):143-57. 
59. Yan RZ, Zhou Q. Coding of "home cage" by PFC neurons. Neuroscience. 2018;393:33-41.

60. Zhou Q, Godwin DW, O'Malley DM, Adams PR. Visualization of calcium influx through channels that shape the burst and tonic firing modes of thalamic relay cells. J Neurophysiol. 1997;77(5):2816-25.

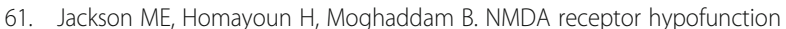
produces concomitant firing rate potentiation and burst activity reduction in the prefrontal cortex. Proc Natl Acad Sci U S A. 2004;101(22):8467-72.

62. Homayoun H, Moghaddam B. NMDA receptor hypofunction produces opposite effects on prefrontal cortex interneurons and pyramidal neurons. J Neurosci. 2007;27(43):11496-500.

63. Chen TWTJ, Yi S, Stefan RP, Sabine LR, Amy B, Eric RS, Rex AK, Michael BO, Vivek J, Loren LL, Karel S, Douglas SK. Ultra-sensitive fluorescent proteins for imaging neuronal activity. Nature. 2013;499(7458):295-300.

64. Atkinson BN, Bell SC, De Vivo M, Kowalski LR, Lechner SM, Ognyanov VI, Tham CS, Tsai C, Jia J, Ashton D, et al. ALX 5407: a potent, selective inhibitor of the hGlyT1 glycine transporter. Mol Pharmacol. 2001;60(6):1414-20.

65. Martina M, Gorfinkel Y, Halman S, Lowe JA, Periyalwar P, Schmidt CJ, Bergeron R. Glycine transporter type 1 blockade changes NMDA receptormediated responses and LTP in hippocampal CA1 pyramidal cells by altering extracellular glycine levels. J Physiol. 2004:557(Pt 2):489-500.

66. Lindsley CW, Wolkenberg SE, Kinney GG. Progress in the preparation and testing of glycine transporter type-1 (GlyT1) inhibitors. Curr Top Med Chem. 2006;6(17):1883-96.

67. Harsing LG, Timar J, Szabo G, Udvari S, Nagy KM, Marko B, Zsilla G, Czompa A, Tapolcsanyi P, Kocsis A, et al. Sarcosine-based Glycine transporter Type-1 (GlyT-1) inhibitors containing Pyridazine moiety: a further search for drugs with potential to influence schizophrenia negative symptoms. Curr Pharm Des. 2015;21(17):2291-303.

68. Hashimoto K. Glycine Transporter-1: a new potential therapeutic target for schizophrenia. Curr Pharm Des. 2011;17(2):112-20.

69. Manahan-Vaughan D, Wildforster V, Thomsen C. Rescue of hippocampal LTP and learning deficits in a rat model of psychosis by inhibition of glycine transporter-1 (GlyT1). Eur J Neurosci. 2008;28(7):1342-50.

70. Chen HH, Stoker A, Markou A. The glutamatergic compounds sarcosine and Nacetylcysteine ameliorate prepulse inhibition deficits in metabotropic glutamate 5 receptor knockout mice. Psychopharmacology. 2010;209(4):343-50.

71. Kumar V, Ahmad MA, Najmi AK, Akhtar M. Effect of Sarcosine (a Glycine transport 1 inhibitor) and Risperidone (an atypical antipsychotic drug) on MK-801 induced learning and memory deficits in rats. Drug Res (Stuttg). 2016;66(1):11-7.

72. Javitt DC, Balla A, Sershen H, Lajtha A. Reversal of phencyclidine-induced effects by glycine and glycine transport inhibitors. Biol Psychiatry. 1999; 45(6):668-79.

73. Kanahara N, Shimizu E, Ohgake S, Fujita Y, Kohno M, Hashimoto T, Matsuzawa D, Shirayama Y, Hashimoto K, lyo M. Glycine and D-serine, but not D-cycloserine, attenuate prepulse inhibition deficits induced by NMDA receptor antagonist MK-801. Psychopharmacology. 2008;198(3): 363-74.

74. Li B, Woo RS, Mei L, Malinow R. The neuregulin-1 receptor ErbB4 controls Glutamatergic synapse maturation and plasticity. Neuron. 2007;54(4):583-97.

75. Du YJ, Grace AA. Amygdala hyperactivity in MAM model of schizophrenia is normalized by Peripubertal diazepam administration. Neuropsychopharmacology. 2016;41(10):2455-62.

76. Ranson A, Broom E, Powell A, Chen F, Major G, Hall J. Top-down suppression of sensory cortex in an NMDAR Hypofunction model of psychosis. Schizophr Bull. 2019;sby190.

77. Uhlhaas PJ, Haenschel C, Nikolic D, Singer W. The role of oscillations and synchrony in cortical networks and their putative relevance for the pathophysiology of schizophrenia. Schizophr Bull. 2008;34(5):927-43.

78. Ford JM, Mathalon DH, Whitfield S, Faustman WO, Roth WT. Reduced communication between frontal and temporal lobes during talking in schizophrenia. Biol Psychiatry. 2002;51(6):485-92.

79. Light GA, Hsu JL, Hsieh MH, Meyer-Gomes K, Sprock J, Swerdlow NR, Braff DL. Gamma band oscillations reveal neural network cortical coherence dysfunction in schizophrenia patients. Biol Psychiatry. 2006;60(11):1231-40.

80. Spencer KM, Nestor PG, Niznikiewicz MA, Salisbury DF, Shenton ME, McCarley RW. Abnormal neural synchrony in schizophrenia. J Neurosci. 2003;23(19):7407-11.

81. Fell J, Axmacher $\mathrm{N}$. The role of phase synchronization in memory processes. Nat Rev Neurosci. 2011;12(2):105-U1500.
82. Gonzalez-Burgos G, Cho RY, Lewis DA. Alterations in cortical network oscillations and parvalbumin neurons in schizophrenia. Biol Psychiatry. 2015; 77(12):1031-40.

83. Marissal T, Salazar RF, Bertollini C, Mutel S, De Roo M, Rodriguez I, Muller D, Carleton A. Restoring wild-type-like CA1 network dynamics and behavior during adulthood in a mouse model of schizophrenia. Nat Neurosci. 2018; 21(10):1412.

84. Sigurdsson T, Stark KL, Karayiorgou M, Gogos JA, Gordon JA. Impaired hippocampal-prefrontal synchrony in a genetic mouse model of schizophrenia. Nature. 2010;464(7289):763-7.

85. Cho RY, Konecky RO, Carter CS. Impairments in frontal cortical gamma synchrony and cognitive control in schizophrenia. Proc Natl Acad Sci U S A. 2006;103(52):19878-83.

86. Morrow BA, Elsworth JD, Roth RH. Repeated phencyclidine in monkeys results in loss of parvalbumin-containing axo-axonic projections in the prefrontal cortex. Psychopharmacology. 2007;192(2):283-90.

87. Belforte JE, Zsiros V, Sklar ER, Jiang Z, Yu G, Li Y, Quinlan EM, Nakazawa K. Postnatal NMDA receptor ablation in corticolimbic interneurons confers schizophrenia-like phenotypes. Nat Neurosci. 2010;13(1):76-83.

88. Woo TUW, Walsh JP, Benes FM. Density of glutamic acid decarboxylase 67 messenger RNA-containing neurons that express the N-methyl-D-aspartate receptor subunit NR2A in the anterior cingulate cortex in schizophrenia and bipolar disorder. Arch Gen Psychiatry. 2004;61(7):649-57.

89. Bitanihirwe BKY, Lim MP, Kelley JF, Kaneko T, Woo TUW. Glutamatergic deficits and parvalbumin-containing inhibitory neurons in the prefrontal cortex in schizophrenia. BMC Psychiatry. 2009;9:71-80,

90. Woo TUW, Kim AM, Viscidi E. Disease-specific alterations in glutamatergic neurotransmission on inhibitory interneurons in the prefrontal cortex in schizophrenia. Brain Res. 2008;1218:267-77.

91. Volk DW, Austin MC, Pierri JN, Sampson AR, Lewis DA. Decreased glutamic acid decarboxylase (67) messenger RNA expression in a subset of prefrontal cortical gamma-aminobutyric acid neurons in subjects with schizophrenia. Arch Gen Psychiatry. 2000;57(3):237-45.

92. Knable MB, Barci BM, Bartko JJ, Webster MJ, Torrey EF. Molecular abnormalities in the major psychiatric illnesses: classification and regression tree (CRT) analysis of post-mortem prefrontal markers. Mol Psychiatry. 2002; 7(4):392-404.

93. Akbarian S, Kim JJ, Potkin SG, Hagman JO, Tafazzoli A, Bunney WE, Jones EG Gene-expression for glutamic-acid decarboxylase is reduced without loss of neurons in prefrontal cortex of schizophrenics. Arch Gen Psychiatry. 1995; 52(4):258-66

94. Lodge DJ, Behrens MM, Grace AA. A loss of Parvalbumin-containing interneurons is associated with diminished oscillatory activity in an animal model of schizophrenia. J Neurosci. 2009;29(8):2344-54.

95. Wang CZ, Yang SF, Xia Y, Johnson KM. Postnatal phencyclidine administration selectively reduces adult cortical parvalbumin-containing interneurons. Neuropsychopharmacology. 2008;33(10):2442-55.

96. Hahn CG, Wang HY, Cho DS, Talbot K, Gur RE, Berrettini WH, Bakshi K, Kamins J, Borgmann-Winter KE, Siegel SJ, et al. Altered neuregulin 1-erbB4 signaling contributes to NMDA receptor hypofunction in schizophrenia. Nat Med. 2006;12(7):824-8.

97. Gu ZL, Jiang Q, Fu AKY, Ip NY, Yan Z. Regulation of NMDA receptors by neuregulin signaling in prefrontal cortex. J Neurosci. 2005;25(20):4974-84.

98. Hardy AM, Urenjak J, Obrenovitch TP. High extracellular Glycine does not potentiate Depolarizations evoked by application of N-methyl-D-aspartate to the rat striatum in-Vivo. Br J Pharmacol. 1995;116:P112.

99. Danysz W, Parsons CG. Glycine and N-methyl-D-aspartate receptors: physiological significance and possible therapeutic applications. Pharmacol Rev. 1998:50(4):597-664.

100. Lanthorn TH. D-Cycloserine - agonist turned antagonist. Amino Acids. 1994; 6(3):247-60

101. Yang FY, Lee YS, Cherng CG, Cheng LY, Chang WT, Chuang JY, Kao GS, Yu L. D-cycloserine, sarcosine and D-serine diminish the expression of cocaine-induced conditioned place preference. J Psychopharmacol. 2013;27(6):550-8.

102. Noda A, Noda Y, Kamei H, Ichihara K, Mamiya T, Nagai T, Sugiura S, Furukawa H, Nabeshima T. Phencyclidine impairs latent learning in mice: interaction between glutamatergic systems and sigma (1) receptors. Neuropsychopharmacology. 2001;24(4):451-60.

103. Yao L, Zhou Q. Enhancing NMDA receptor function: recent progress on allosteric modulators. Neural Plast. 2017;2017:2875904. 
104. Hackos DH, Hanson JE. Diverse modes of NMDA receptor positive allosteric modulation: Mechanisms and consequences. Neuropharmacology. 2017; 112(Pt A):34-45.

105. Monaghan DT, Irvine MW, Costa BM, Fang G, Jane DE. Pharmacological modulation of NMDA receptor activity and the advent of negative and positive allosteric modulators. Neurochem Int. 2012;61 (4):581-92.

106. Costa BM, Irvine MW, Fang G, Eaves RJ, Mayo-Martin MB, Skifter DA, Jane $D E$, Monaghan DT. A novel family of negative and positive allosteric modulators of NMDA receptors. J Pharmacol Exp Ther. 2010;335(3):614-21.

107. Wang TM, Brown BM, Deng LB, Sellers BD, Lupardus PJ, Wallweber HJA, Gustafson A, Wong E, Volgraf M, Schwarz JB, et al. A novel NMDA receptor positive allosteric modulator that acts via the transmembrane domain. Neuropharmacology. 2017;121:204-18.

108. Hackos DH, Lupardus PJ, Grand T, Chen Y, Wang TM, Reynen P, Gustafson A, Wallweber $\mathrm{HJ}$, Volgraf $\mathrm{M}$, Sellers BD, et al. Positive allosteric modulators of GluN2A-containing NMDARs with distinct modes of action and impacts on circuit function. Neuron. 2016;89(5):983-99.

109. Papouin T, Ladepeche L, Ruel J, Sacchi S, Labasque M, Hanini M, Groc L, Pollegioni L, Mothet JP, Oliet SH. Synaptic and extrasynaptic NMDA receptors are gated by different endogenous coagonists. Cell. 2012;150(3): 633-46.

\section{Publisher's Note}

Springer Nature remains neutral with regard to jurisdictional claims in published maps and institutional affiliations.

Ready to submit your research? Choose BMC and benefit from:

- fast, convenient online submission

- thorough peer review by experienced researchers in your field

- rapid publication on acceptance

- support for research data, including large and complex data types

- gold Open Access which fosters wider collaboration and increased citations

- maximum visibility for your research: over $100 \mathrm{M}$ website views per year

At $\mathrm{BMC}$, research is always in progress.

Learn more biomedcentral.com/submissions 